\title{
PENGGUNAAN ALAT TANGKAP SENGKIRAI BILAH DI PERAIRAN LUBUK LAMPAM, SUMATERA SELATAN
}

\author{
Burnawi'1) \\ 1) Teknisi Litkayasa pada Balai Riset Perikanan Perairan Umum, Mariana-Palembang \\ Teregristasi I tanggal: 15 Agustus 2006; Diterima setelah perbaikan tanggal: 4 Juni 2007; \\ Disetujui terbit tanggal: 8 Juni 2007
}

\section{PENDAHULUAN}

Perairan umum lubuk lampam dengan (luas \pm 1.200 ha) merupakan daerah aliran sungai bagian dari Sungai Lempuing yang terletak $25 \mathrm{~km}$ sebelah tenggara Kota Kayu Agung ibu kota Kabupaten Ogan Komering Ilir. Sepanjang daerah aliran Sungai Lempuing merupakan perairan rawa lebak flood flain yang berfungsi sebagai daerah penangkapan ikan di Kabupaten Ogan Komering llir (Arifin, 1978).

Kegiatan penangkapan ikan di perairan Lubuk Lampam menggunakan alat tangkap tradisional seperti sengkirai bilah, pengilar rotan, pengilar kawat, tuguk, jala, tangkul, pukat, dan tajur. Di antara alat-alat tersebut, maka yang sering digunakan nelayan di lubuk lampam adalah sengkirai bilah. Alat tangkap ini terbuat dari bilah bambu yang dianyam dengan tali plastik atau rotan pada bagian depan bentuk persegi dan pada bagian belakang berbentuk oval dan pada bagian depan dipasang injab, bersifat menjebak (traps), dan statis (Akrimi, 1999).

Menurut Prasetyo (1996), pengoperasian alat tangkap di perairan umum dipengaruhi oleh musim (kemarau maupun penghujan) musim penangkapan ikan menggunakan alat tangkap sengkirai bilah pada musim penghujan bulan Nopember sampai dengan Maret.

Tujuan penulisan ini untuk menguraikan cara membuat sengkirai bilah dan cara pengoperasian alat tersebut di rawa lebak lubuk lampam Kabupaten Ogan Komering Ilir, Sumatera Selatan.

\section{POKOK BAHASAN}

Penulisan makalah ini berdasarkan pada wawancara langsung dengan kelompok nelayan setempat. Alat tangkap sengkirai bilah ini telah digunakan secara turun-temurun oleh nelayan di lubuk lampam. Cara pembuatan dan pengoperasian alat ini sebagai berikut:

\section{Bahan}

Bahan baku yang digunakan untuk membuat sengkirai bilah antara lain bambu dan tali plastik.

\section{Alat}

Alat yang digunakan untuk membuat sengkirai bilah antara lain pisau, gergaji, dan meteran.

Spesifikasi alat tangkap sengkirai bilah (Gambar

1) sebagai berikut:

1. Tinggi: $60 \mathrm{~cm}$.

2. Lebar: $40 \mathrm{~cm}$.

3. Tebal: $30 \mathrm{~cm}$.

4. Bahan utama: bambu.

5. Waktu pengoperasian alat pada musim penghujan.

6. Tempat pengoperasian alat tangkap di rawa lebak.

7. Bersifat statis dan menjebak (traps).

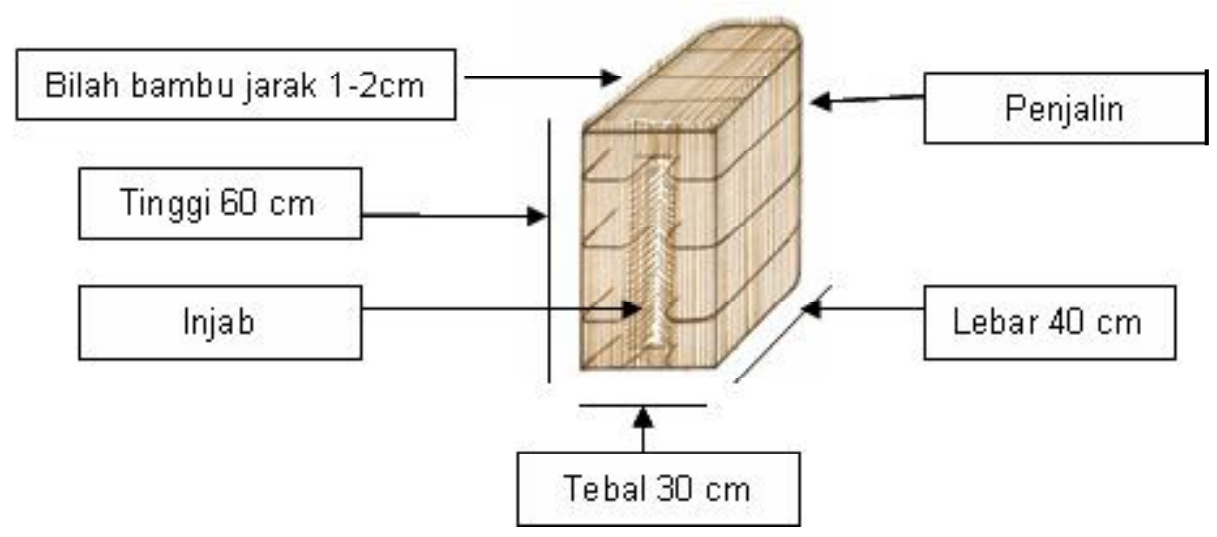

Gambar 1. Alat tangkap sengkirai bilah. 


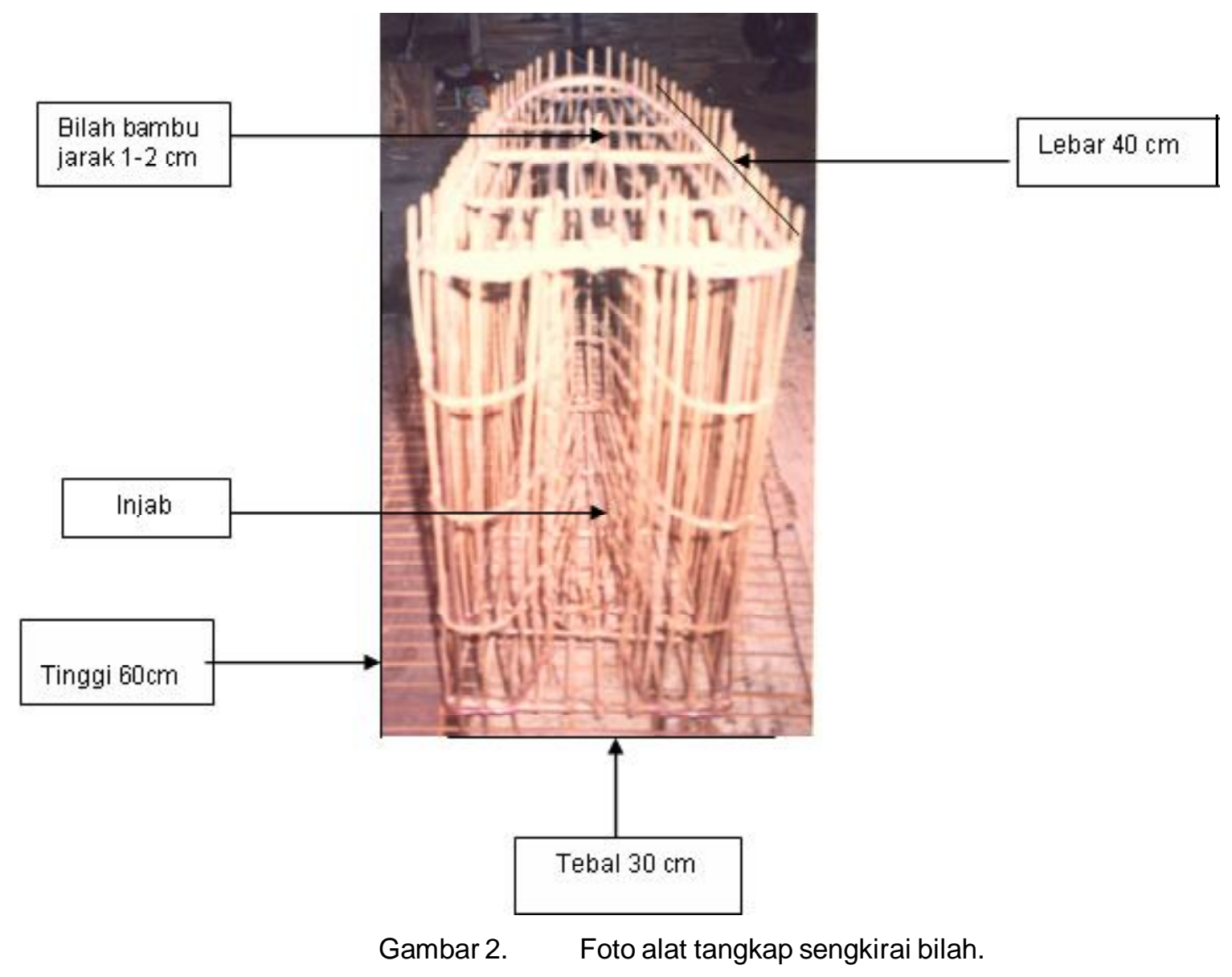

\section{Cara Pembuatan}

1. Bambu yang telah cukup tua dan lurus semua dibersihkan ranting-ranting dengan menggunakan pisau. Bambu dijemur selama \pm 15 hari sampai dengan kering untuk mempermudah mengerjakan dan agar lebih awet.

2. Bambu dipotong menggunakan gergaji sepanjang $60 \mathrm{~cm}$ kemudian dibelah memakai pisau dengan menjadi ukuran panjang $60 \mathrm{~cm}$, lebar $0,5 \mathrm{~cm}$, dan tebal $2 \mathrm{~mm}$, kemudian diraut sampai dengan cukup halus sehingga menjadi bilah-bilah kecil dan tipis.

3. Bilah-bilah dijalin dengan tali plastik dengan jarak antara bilah $\pm 1 \mathrm{~cm}$ dan jarak antara tali penjalin $20 \mathrm{~cm}$ dibentuk seperti bidai panjang $120 \mathrm{~cm}$ (Gambar 2).

4. Selanjutnya pembuatan bingkai bilah bambu dengan ukuran lebar $1,5 \mathrm{~cm}$ dan panjang $120 \mathrm{~cm}$ dibentuk seperti huruf $U$ dan bilah-bilah bambu ukuran panjang $30 \mathrm{~cm}$ dijalinkan pada bambu tersebut (Gambar 3).

5. Pembuatan injab bilah dengan cara diraut sampai dengan runcing seperti huruf $\mathrm{V}$ yang tajam panjang $20 \mathrm{~cm}$, lebar $2 \mathrm{~mm}$, dan tebal $2 \mathrm{~mm}$. Injab berfungsi sebagai alat penjebak agar ikan tidak dapat ke luar dari alat tangkap sengkirai bilah tersebut (Gambar 4).
6. Merangkai bidai (anyaman bilah bambu) dijalin pada kerangka yang berbentuk huruf $U$ dirangkai satu per satu.

7. Bidai ini berfungsi sebagai bahan utama untuk menutupi pola yang telah dibentuk seperti huruf $U$ tersebut sehingga ikan yang masuk dalam sengkirai bilah tersebut tidak dapat ke luar.

8. Pemasangan injab dan dirangkaikan juga pada kerangka bentuk huruf $V$ yang tajam sehingga terbentuk sengkirai bilah yang sedemikian rupa.

\section{Alat Bantu Penangkapan}

Alat bantu penangkapan terdiri atas perahu kayu, panjang $3 \mathrm{~m}$, lebar $50 \mathrm{~cm}$, tinggi $40 \mathrm{~cm}$, dan bahan kayu merantih.

\section{Cara Pemasangan}

1. Sengkirai bilah dimasukkan ke dalam perahu dan dibawa ke lokasi penangkapan yang telah ditentukan.

2. Waktu pagi hari sekitar pukul 7.00 sampai dengan 8.00 WIB sengkirai bilah dipasang di daerah rawa lebak sampai dengan kedalaman air $50 \mathrm{~cm}$, dipasang secara tegak mengikuti alur-alur yang ditumbuhi dengan tumbuhan air seperti enceng gondok dan kumpai di tengah rawa (lebak).

3. Bagian depan sengkirai bilah dimasukkan ke dalam air dengan kedalaman $40 \mathrm{~cm}$, dan dipasang secara tegak. 
4. Agar bagian depan sengkirai bilah tersebut tenggelam ke dalam air dan tidak bergerak secara leluasa ke kiri dan ke kanan, maka perlu dipasang alat bantu satang (stick) bambu yang ditusukkan di antara bilah-bilah di bagian pinggir sengkirai bilah yang ditancapkan ke dalam tanah sampai dengan kedalaman 10 sampai dengan $15 \mathrm{~cm}$.

5. Satang (stick) adalah bambu tempat mengikatkan sengkirai bilah dengan ukuran panjang $2,5 \mathrm{~m}$, berdiameter 1 sampai dengan $2 \mathrm{~cm}$, sebagai alat bantu agar sengkirai bilah tersebut tidak timbul ke permukaan air, bergerak ke kiri dan ke kanan.

6. Bagian atas sengkirai bilah tersebut timbul di permukaan air dengan tujuan supaya ikan yang tertangkap tidak mati lemas karena kekurangan oksigen.

\section{Pengambilan Hasil Tangkapan}

1. Pada pagi hari sengkirai bilah dilihat satu per satu diangkat ke atas permukaan air bila ada ikan yang terperangkap, maka sengkirai bilah tersebut dimasukkan ke dalam perahu.

2. Ikan tertangkap dikeluarkan dari dalam alat tangkap sengkirai bilah dengan cara membuka injab bagian depan secara perlahan-lahan dan dimiringkan kemudian ikan dimasukkan ke dalam perahu yang telah diisi air dengan kedalaman air 2 sampai dengan $5 \mathrm{~cm}$.

3. Setelah itu sengkirai bilah dipasang kembali seperti semula.

4. Ikan yang tertangkap dengan memakai alat tangkap sengkirai bilah adalah jenis ikan gabus (Channa striata).

5. Hasil tangkapan nelayan berkisar 4 sampai dengan $15 \mathrm{~kg}$ per hari atau 100 sampai dengan 150 sengkirai bilah.

\section{KESIMPULAN}

1. Sengkirai bilah adalah alat tangkap yang efektif dan selektif yang digunakan oleh nelayan di perairan lubuk lampam, Sumatera Selatan.

2. Ikan yang tertangkap dengan memakai alat tangkap sengkirai bilah adalah jenis ikan gabus (Channa striata).

3. Ikan hasil tangkapan berkisar 4 sampai dengan $15 \mathrm{~kg}$ per orang per hari atau 100 sampai dengan 150 sengkirai bilah.

\section{DAFTAR PUSTAKA}

Arifin, Z. 1978. Beberapa aspek tentang penangkapan ikan di perairan lubuk lampam. Simposium Moderenisasi Perikanan Rakyat. Lembaga Penelitian Perikanan Darat Cabang Palembang. Jakarta. 27-30 Juni 1978.

Akrimi. 1999. Alat tangkap tadisional di perairan lubuk lampam, Sumatera Selatan. Buletin Teknik Pertanian. Badan Penelitian dan Pengembangan Pertanian. Jakarta.Vol.IV. No.2. Hal.76-79.

Prasetyo, D. \& A. D. Utomo. 1996. Pelestarian sumber daya plasmah nutfah perairan umum. Jurnal Penelitian dan Pengembangan Pertanian. $\mathrm{X}(4)$ : 90-96.

\section{UCAPAN TERIMA KASIH}

Melalui kesempatan ini penulis mengucapkan terima kasih pada Bapak Nuriman yang telah membantu dalam mengumpulkan data dan sebagai narasumber sampai dengan terlaksana tulisan ini. 